\title{
O caráter interacional e intertextual da argumentação polêmica
}

\section{The interactional and intertextual character of the polemic argument}

\author{
Mônica Magalhães Cavalcante ${ }^{1}$ \\ Mariza Angélica Paiva Brito ${ }^{2}$ \\ Evandro de Melo Catelão ${ }^{3}$ \\ Maria da Graça dos Santos Faria ${ }^{4}$ \\ Ananias Agostinho da Silva ${ }^{5}$ \\ Suzana Leite Cortez ${ }^{6}$
}

Resumo: Os critérios analíticos da Linguística Textual são motivados por uma tentativa de explicação para as escolhas textuais por meio das quais o sujeito age sobre o seu dizer, reelaborando-o a todo instante, negociando-o com os prováveis interlocutores (em seus papéis sociais), para buscar atender a seus propósitos (CAVALCANTE et alii, 2020). É justamente a suposição dessa agentividade, dessa actorialização, que faz a LT eleger como critérios de análise os diversos recursos de que pode se valer o locutor para tentar persuadir a quem ele projeta como interlocutor e, muitas vezes, como terceiro. Analisamos as marcas da negociação dos conflitos entre pontos de vista antagônicos que acontecem nas modalidades argumentativas polêmicas, admitindo amplamente que, nas interações humanas, os interlocutores mobilizam recursos tecnolinguageiros, em ambientes digitais, nas diversas tentativas de reafirmar seu ponto de ponto de vista no dissenso e de influenciar o terceiro. Enfatizamos, neste trabalho, dois traços da modalidade argumentativa da polêmica que merecem ser aprofundados ainda. $\mathrm{O}$ primeiro é o fato de a noção de polêmica de Amossy (2017) se descrever não como uma oposição discursiva pela qual todo discurso se identifica, mas como um dos tipos de modalidade argumentativa, o que exige que a polêmica aconteça numa interação concreta, em que os participantes encenam o papel social de Proponente, de Oponente e de Terceiro. O segundo é o fato de a intertextualidade não ser um recurso opcional nessa modalidade, mas uma condição para que o embate se efetive no espaço público.

Palavras-chave: Argumentação polêmica. Interação. Encenação. Intertextualidades.

Abstract: The analytical criteria of Textual Linguistics are motivated by an attempt to explain the textual choices through which the subject acts on their saying, re-elaborating it at all times, negotiating it with the probable interlocutors (in their social roles), in order to seek to meet their purposes (CAVALCANTE et alii, 2020). It is precisely the assumption of this agentivity, of this actorialization, that makes Textual Linguistics choose as analysis criteria the various resources that the speaker can use to try to persuade whom they project as an interlocutor and,

\footnotetext{
${ }^{1}$ Universidade Federal do Ceará, Centro de Humanidades, Departamento de Linguística, Programa de PósGraduação em Linguística, Fortaleza, CE, Brasil. Endereço eletrônico: monicamc02@gmail.com.

${ }^{2}$ Universidade da Integração Internacional da Lusofonia Afro-Brasileira, Instituo de Linguagens e Literaturas, Departamento de Linguística, Programa de Pós-Graduação em Estudos da Linguagem, Redenção, CE, Brasil. Endereço eletrônico: marizabrito02@gmail.com.

${ }^{3}$ Universidade Tecnológica Federal do Paraná, Curso de Letras, Departamento de Linguagem e Comunicação, Programa de Pós-Graduação em Estudos da Linguagem, Curitiba, PA, Brasil. Endereço eletrônico: evandrocatelao@gmail.com.

${ }^{4}$ Universidade Federal do Maranhã, Centro de Ciências Humanas, Curso de Letras, Departamento de Letras, Programa de Pós-Graduação em Letras, São Luís, MA, Brasil. Endereço eletrônico: gracafaria@ hotmail.com.

5 Universidade Federal Rural do Semi-Árido, Centro Multidisciplinar de Angicos, Curso de Pedagogia, Departamento de Ciências Humanas, Programa de Pós-Graduação em Ensino, Angicos, RN, Brasil. Endereço eletrônico: ananias.silva@ufersa.edu.br.

${ }^{6}$ Universidade Federal de Pernambuco, Centro de Artes e Comunicação, Curso de Letras, Departamento de Letras, Programa de Pós-Graduação em Letras, Recife, PE, Brasil. Endereço eletrônico: sucortez@ gmail.com.
} 
often, as a third party. We analyzed the marks of the negotiation of conflicts between the antagonistic points of view that take place in the polemic argumentative modalities, broadly admitting that, in human interactions, the interlocutors mobilize technolanguage resources, in digital environments, in their several attempts to reaffirm their point of view in the polemic and to influence the third party. We emphasize, in this study, two features of the argumentative modality of the controversy that deserve to be further explored. The first is the fact that Amossy's (2017) notion of polemic is described not as a discursive opposition by which every discourse is identified, but as one of the types of argumentative modality, which requires the polemic to happen in a concrete interaction, in which the participants enact the social role of Proponent, Opponent and Third Party. The second is the fact that the intertextuality is not an optional resource in this modality, but a condition for the conflict to take place in the public space.

Keywords: Argumentation. Interaction. Mis-en-scene. Intertextuality.

\section{Introdução}

A argumentação, segundo Amossy (2017; 2020), situa-se num quadro onde os participantes de uma interação buscam agir um sobre o outro, nem que seja apenas para predispor o outro a ver e pensar de determinada maneira. Desse modo, nas interações em que se defende uma tese, tenta-se apoiá-la num conjunto de argumentos, claramente explicitados ou não e, neste caso, dizemos que os textos que dali emergem, apresentam visada argumentativa. Nas interações em que não se tenta demonstrar uma tese, ainda assim há pontos de vista de algum modo expressos que orientam o outro para dados modos de pensar, de ver e de sentir. Dizemos que os textos desse tipo de interação apresentam somente uma dimensão argumentativa.

Em outras palavras, a argumentação é inerente a qualquer texto, e toda interação atende a determinados modos de argumentar, desde os moderados aos mais exacerbados, como propõe Amossy (2008). Dentre essas modalidades argumentativas, focalizamos, neste trabalho, a modalidade polêmica, caracterizada pela autora a partir de uma perspectiva ao mesmo tempo retórica e discursiva. Amossy (2017) sugere para a polêmica, vista como dissenso absoluto, três propriedades fundamentais: a dicotomização, a polarização e a desqualificação do oponente.

Nosso propósito aqui é tecer considerações sobre dois aspectos que nos parecem condicionar a modalidade argumentativa polêmica. O primeiro é o fato de a polêmica só se efetivar em situações concretas de uso, em que atores sociais interagem e encenam papéis sociais de proponente, oponente e terceiro. O segundo é o fato de essa modalidade argumentativa requerer, necessariamente, diálogos intertextuais, nos quais, muitas vezes se destacam as copresenças, as alusões amplas e a metatextualidade. 


\section{O caráter interacional da polêmica}

Ao propor a teoria da argumentação nos discursos, Ruth Amossy delineou um caminho teórico-metodológico que permite apreender a argumentação (até então, negligenciada pelos estudos do discurso) em seus quadros discursivos e institucionais. Nosso interesse pela teoria da argumentação nos discursos adveio da necessidade de explicar as razões pelas quais os critérios analíticos da Linguística Textual poderiam todos estar relacionados à dinâmica interacional, aos cruzamentos de pontos de vista pelos quais se entrevê a interdiscursividade e aos jogos estratégicos da argumentação persuasiva.

Como observa Amossy (2017), para que fosse possível a interface entre a análise do discurso, com a qual a autora se identifica, e os pressupostos da retórica, era necessário pensar num sujeito retórico ressignificado, pois, do contrário, as duas abordagens teóricas seriam incompatíveis. Se o sujeito da AD não é dono de sua vontade, porque ou é coagido por forças ideológicas e discursivas, ou está submetido a uma inconsciência que lhe é constitutiva, por outro lado o sujeito da retórica se mostra soberano, porque governa a si e a seus textos, sendo capaz de utilizar conscientemente a língua para influenciar e persuadir outros sujeitos.

O sujeito da teoria da argumentação nos discursos (doravante, TAD) é um pouco de um e um pouco de outro - talvez possamos dizê-lo. Ele é involuntariamente determinado pela fala social na qual está imerso. Mas também é estrategista, por isso alimenta a doce ilusão de que tem domínio sobre tudo o que diz. No âmbito da TAD, o sujeito é considerado, conforme o papel social que desempenha, como elaborador de um projeto persuasivo constrangido por fatores de ordem social, pelos rituais dos gêneros e pelo pertencimento de sua fala a uma significação social dotada de lugares comuns e de argumentos próprios. Antes mesmo de buscar influenciar o outro, persuadindo-o ou não, ele próprio toma uma posição frente a uma doxa que está subentendida em seu projeto de dizer. É por isso que os discursos e os modos de pensar e de dizer o mundo do locutor são necessariamente vistos como uma resposta, ainda que implícita, a palavras alheias ditas anteriormente. Todo ato de o locutor se instituir como sujeito é, portanto, inapelavelmente dialógico. O dialogismo bakhtiniano subjaz, assim, à proposta da TAD.

É a partir da inscrição do sujeito nessa fala social e em valores dóxicos que ele busca orientar o olhar do outro, a fim de, pelo menos, predispô-lo a uma determinada ação. Amossy (2005) acrescenta que o estatuto do locutor e o quadro institucional no qual ele profere sua fala também têm importância para essa concepção de sujeito ao mesmo tempo livre e coagido, porque seu discurso não somente é uma resposta a um já dito, como também reflete uma engrenagem social que o autoriza ou não a um dizer, a depender da posição e do grau de 
legitimidade de que desfruta esse locutor no contexto em que escolheu intervir (MACEDO, 2018).

A concepção de sujeito da retórica repousaria sobre dois pressupostos inadmissíveis:

1) que apenas o auditório é condicionado em uma argumentação;

2) e que o orador é o "dono" da tese, ou seja, que ele tem pleno domínio sobre seu discurso, sua opinião, seu ponto de vista.

$\mathrm{A} \mathrm{TAD}$, que, para nós, integra à $\mathrm{AD}$ francesa muitas concepções de uma abordagem semiolinguística do discurso, de base charaudiana, reconfigura esse sujeito retórico autônomo e plenamente consciente, concebendo-o como uma instância enunciativa constrangida pela doxa que o circunda e tributária dos quadros institucionais nos quais ele se situa (AMOSSY, 2005). Para além de um estrategista que busca sempre influenciar o outro, como se lê em Charaudeau (2016), o sujeito da TAD lança mão de um conjunto de recursos linguageiros que investem em seleções de argumentos e mobilizam as provas do ethos e do pathos.

Amossy (2020) dá relevo à função positiva da retórica na vida da sociedade: um meio democrático de tomar decisões coletivas, ou mesmo individuais, e de expressar pontos de vista diferentes. A autora defende uma retórica do plausível. Argumentar é um exercício mútuo de influências entre os participantes de uma interação, e uma tentativa de agir sobre o outro e de predispô-lo a reagir de algum modo.

\section{Distinguimos tese de ponto de vista}

Concebemos os termos "tese" e "ponto de vista" distintamente. O ponto de vista é como uma perspectivização semiotizada dos referentes de um texto, e estará sempre a eles relacionada. Todo texto deixa entrever, portanto, diferentes pontos de vista, diferentes modos de um locutor se colocar na apresentação e nas retomadas recategorizadoras dos referentes em um texto. Só utilizamos o termo tese quando lidamos com textos de sequência argumentativa dominante, pois é nesse modo de organização composicional de um texto que se apresenta uma proposição que deverá estar, implícita ou explicitamente, apoiada em argumentos.

Utilizamos os termos tese e ponto de vista, para nos referirmos, respectivamente, à opinião estrategicamente defendida por um locutor (baseada em argumentos) com vista à sua adesão pelo auditório e à expressão de um modo particular de ver as coisas, que é inerente a todo e qualquer dizer. Tomando por base as considerações de Plantin (2016), em "Dictionnaire de l'argumentation", o argumento é orientado para a conclusão, enquanto que a conclusão é a projeção do argumento, o que faz com que o argumento acompanhe a resposta a uma questão 
argumentativa", ao passo que a tese seja a própria resposta à questão argumentativa que se coloca.

A nosso ver, esse enfoque sistemático da relação argumento-conclusão descrita por Plantin (2016) possibilita considerar o caráter planejado da tese, que, para ser construída e forrada em argumentos, necessita guiar-se pelo acordo social atrelado ao padrão sociorretórico do gênero. Nesse sentido, podemos dizer que a tese é marcadamente manifesta e reconhecida em gêneros de visada argumentativa (debates, artigos de opinião, redações de concurso, petições, etc., isto é, aqueles que convocam sequência argumentativa para a sua organização composicional).

Contudo, isto não significa dizer que gêneros desta natureza não comportem pontos de vista. Como dissemos, se pontos de vista são modos de ver e de sentir os referentes, e se todo texto se tece em torno de referentes, então todo texto expressa pontos de vista. Na verdade, a própria tese não deixa de ser um tipo de ponto de vista, aquele que, em textos de visada argumentativa, é a conclusão para a questão-problema que o locutor discute.

No entanto, o termo tese não é uma noção teórica problematizada e bem definida em estudos linguísticos da argumentação. Como vemos no dicionário de Christian Plantin, ela é tangencial e associada a outros termos - argumento, conclusão e ponto de vista. Embora tese e ponto de vista não sejam verbetes específicos nessa obra, eles aparecem na subseção "3. Thèse, conclusion, point de vue", do verbete argumento" (PLANTIN, 2016, p. 70). A obra apresenta os termos como sinônimos a depender da área de conhecimento, e essas confluências e imprecisões nos levam a insistir na necessidade de distinção entre tese e ponto de vista.

A noção de ponto de vista (PDV), por sua vez, é discutida no âmbito dos estudos de polifonia, dentre os quais salientamos o de Alain Rabatel cujos trabalhos têm se dedicado a analisar formas muito diversas de PDV - seja daqueles que se apresentam como opinião explícita, seja daqueles que, mesmo não se apresentando explicitamente, podem ser flagrados por modos muito diversos de expressão: pelas escolhas das formas de referenciação, pelas escolhas verbais; pela seleção dos conectores; pelas escolhas de organização da predicação (ordem das palavras, ênfase etc.) e pela organização retórica de diversos enunciados em um texto etc. (RABATEL, 2012). A essas formas mais "mascaradas" de perspectivação é que o autor mais tem se dedicado, concebendo-as como formas de argumentação indireta, em que se argumenta sem parecer que é argumentativo, o que se relaciona ao que Amossy concebe como dimensão argumentativa.

De uma noção mais estrita de PDV, limitada aos meios de expressão da percepção na narrativa literária, o autor amplia a noção estendendo-a às mais variadas formas, que, nos mais 
diversos gêneros, evidenciam a referência ao objeto de discurso e à reação do enunciador a este objeto: "em outras palavras, há PDV quando a referenciação revela os objetos do discurso indicando o ponto de vista do enunciador sobre esse(s) mesmo(s) objeto(s)"7 (RABATEL, 2018, p. 128).

Assim, como dissemos em outros trabalhos (CORTEZ, 2011; PINTO; CORTEZ, 2017), o PDV necessariamente conecta o enunciador ao objeto de discurso sempre em relação com outros enunciadores, o que reforça o caráter dialógico da noção, pois, para Rabatel ([2008]2016), as relações entre locutor e enunciador estão na base da noção de ponto de vista. Por essa razão, o PDV é um fenômeno de heterogeneidade enunciativa, o que o torna mais abrangente que o termo tese.

\section{A argumentação vista num continuum}

A concepção de argumentação adotada por Amossy é alargada e, nesse sentido, distingue-se da forma como é concebida na Nova Retórica. Se, em Perelman e Olbrechts-Tyteca (2005, p. 4), a argumentação é tomada como a tentativa de "provocar ou aumentar a adesão dos espíritos às teses que se lhes apresentam ao assentimento", em Amossy, é entendida como sendo "a tentativa de modificar, de reorientar, ou mais simplesmente de reforçar, pelos recursos da linguagem, a visão das coisas da parte do alocutário", ou seja, como a "tentativa de fazer aderir não somente a uma tese, mas também a modos de pensar, de ver, de sentir" (AMOSSY, 2011, p. 30). Assim sendo, a argumentação não supõe somente os discursos de finalidade persuasiva, mas os variados tipos de trocas argumentativas que se desenvolvem nos mais diversos gêneros do discurso.

No quadro da Linguística Textual, alinhamo-nos à perspectiva de Amossy, que substitui a clássica oposição "argumentativo" versus "não argumentativo" pela concepção de modalidades e modos de argumentatividade. Para a autora, toda troca verbal acontece a partir de um jogo de influências mútuas e de uma tentativa, relativamente consciente e expressa, de usar o discurso para agir sobre o outro. Consequentemente, nenhum texto é neutro do ponto de vista discursivo e argumentativo, ou seja, todo enunciado reflete um posicionamento que se pretende fazer prevalecer sobre outro(s), ainda que o debate seja tácito e latente. A tentativa de influenciar o outro, persuadindo-o ou não, é uma condição de qualquer texto. Ainda que não defenda uma tese explicitamente, o texto estará sempre fundado em pontos de vista. E terá sempre uma dimensão argumentativa.

\footnotetext{
${ }^{7}$ Tradução livre do trecho: "autrement dit, il y a PDV lorsque la référenciation dénote le ou les objets du discours tout en renseignant sur le point de vue de l'énonciateur sur ce(s) même(s) objet(s)".
} 
É por isso que, por inspiração em Amossy, preferimos falar em textos de visada argumentativa e textos de dimensão argumentativa - ainda que essa relação não se dê por oposição. Nos textos de visada argumentativa, o locutor busca declaradamente defender uma tese e, para tal, arranja um arrazoado de argumentos em torno dela, visando persuadir o interlocutor. É exatamente o que acontece em textos de gêneros como o debate público, o artigo de opinião, a redação do ENEM, dentre outros cuja organização composicional se orienta pela estruturação de uma sequência argumentativa dominante. Por outro lado, todos os demais textos que não têm essa configuração apresentam uma dimensão argumentativa, porque sempre orientam um modo particular de se conceber as coisas ou as ideias.

Em todo caso, a argumentação é sempre constitutiva dos textos, mesmo que o seja de formas diferentes. É por essa razão que Amossy (2008) elabora a noção de modalidade argumentativa para se referir aos diversos "tipos de trocas argumentativas que, atravessando os gêneros do discurso, modelam a forma como a argumentação funciona tanto num quadro dialogal quanto num dialógico" (p. 232). Essa ideia aponta para uma concepção modular de argumentação, que pode ser vista na perspectiva de um continuum no qual as modalidades argumentativas variam do acordo ao desacordo, da conformidade ao choque antagônico de opiniões, sendo condicionadas pelos gêneros do discurso e pelas restrições de cada quadro interacional.

Cada modalidade revela maneiras particulares de se argumentar que, de acordo com Amossy (2008), podem ser caracterizadas a partir de parâmetros como os papéis desempenhados pelos participantes no dispositivo enunciativo (parceiros, adversários), a maneira pela qual ocorre a tentativa de persuasão (apaixonada, racional, colaborativa, instrutiva) e o modo como o interlocutor é concebido (ser de razão e/ ou de sentimento, aluno ou discípulo, cúmplice ou rival etc.). Aqui, tratamos especificamente da modalidade polêmica.

\section{As propriedades da argumentação polêmica}

As reflexões de Ruth Amossy sobre a descrição de uma modalidade argumentativa polêmica se apoiam em algumas ideias de Dascal e Knoll (2011) sobre polêmicas públicas. Os autores, embora se debrucem sobre a caracterização de um dispositivo cognitivo e verbal que bloqueia o acordo nas controvérsias, sugerem que se dedique um olhar diferenciado para as polêmicas públicas como "controvérsias arrazoadas". Dascal e Knoll empregam o termo "dicotomização sistêmica cognitiva" para se referirem ao fenômeno social de intercognição que subjaz à criação e manutenção de visões de mundo cognitivas coletivas, ou seja, a sistemas de valores e pontos de vista em uma comunidade, qualquer que seja seu tipo. Essas dicotomizações 
se organizam a partir de conhecimentos esquematizados em cenários sociais e políticos complexos e envolvem também impactos afetivos, além de surtirem efeito na formação de identidades coletivas.

As dicotomizações, como vemos, estão num nível de subjacência, de relações dialógicas no espaço público e, em vista disso, a nosso ver, elas podem, a todo momento, ser atualizadas, geralmente por meio de alusões amplas, ou, dependendo da ocorrência, por meio de apelos intertextuais mais específicos a determinados textos.

Para Dascal e Knoll (2011), é possível usar uma argumentação arrazoada não exatamente para superar a diferença de opiniões e chegar ao acordo - fincavam-se nesse tipo de visão as raízes do que Amossy proporia, em 2014, como modalidade argumentativa polêmica.

Outro dos autores que exerceram influência sobre a proposta de Amossy foi Christian Kock, para quem o dissenso deve ser analisado como um fator positivo, como "controvérsias construtivas". Kock (2009) advoga em favor de uma concepção de democracia fundada no dissenso, não no consenso, e sustenta uma definição mais estrita de retórica, ligada a uma argumentação prática, que se preocupa com os temas vistos não como verdades imutáveis, mas como diferentes posicionamentos frente às representações sociais. Para o autor, nunca haverá uma regra de que os argumentadores não podem discordar sobre uma dada escolha proposta, nem será ilegítimo argumentar estrategicamente.

Segundo Amossy (2017), Kock não privilegia, no entanto, o dissenso na polêmica pública, e é precisamente isso que ela tenta fazer no livro Apologia da polêmica, ao caracterizar a modalidade argumentativa polêmica como uma retórica do dissenso, como "uma gestão do conflito de opinião sob o modo da dissidência, e não de uma busca de acordo" (p. 41).

Para diferenciar a modalidade argumentativa polêmica do desacordo comum, Amossy (2017) sugere três propriedades fundamentais: a dicotomização, a polarização e a desqualificação do outro. Influenciada, assim, por Dascal e Knoll, Amossy esclarece que, enquanto no debate comum os participantes se direcionam para uma possibilidade de solução, na polêmica pública a dicotomização supõe uma dissensão radical, por isso, durante a polarização entre as partes, a solução se mostra impossível. Entendemos, neste trabalho, a propriedade de dicotomização como sendo da ordem da interdiscursividade, e, no caso da modalidade polêmica, ela é pressuposta como um antagonismo profundo (Amossy a vê como uma operação abstrata).

Pensamos que é, na verdade, pela propriedade de polarização que a polêmica realmente se atualiza no espaço público, pois é no acontecimento dos textos que a interação se efetiva. 
São os atores sociais, agindo como interlocutores, que se posicionam no debate irresolvível como um dos papéis actanciais: de Proponente (defensor da posição proposta), de Oponente (opositor dessa tese), ou de Terceiro (ouvinte-espectador da confrontação). Citando King e Floyd (1971), Amossy define a polarização como um processo em que um público extremamente diversificado se divide em dois grupos cujas opiniões se contrastam e se excluem mutuamente.

Durante a interação em que os atores sociais se polarizam, dois movimentos se percebem: um de reagrupamento por identificação, quando os supostos defensores da posição proposta são colocados como tendo um inimigo comum; outro de difamação do opositor e do grupo que ele representa. São essas últimas manobras para desacreditar o adversário que constituem a terceira propriedade da polêmica: a desqualificação do outro. Queremos ressaltar que também essa propriedade só acontece na realização dos textos, concretamente. Esses usos linguageiros desqualificadores são, pois, uma consequência inevitável da polarização que atualiza as teses dicotomizadas. O objetivo dos atores sociais que representam grupos polarizados é deslegitimar o opositor, refutando-lhe os argumentos, rebaixando-o e até buscando colocá-lo fora da disputa.

\section{O caráter eminentemente intertextual da modalidade polêmica}

Quando intenta responder a como a polêmica se manifesta nos textos que a mídia faz circular no espaço público, Amossy (2016) se concentra em três casos interacionalmente distintos. Para nós, em todas as situações, o recurso às intertextualidades é uma condição de instauração da modalidade polêmica. A primeira forma de estabelecer a polêmica analisada por Amossy é apresentada como uma interação monogerida (a que a autora chama de "discurso polêmico"), exemplificada por um artigo de opinião publicado em uma revista de circulação nacional. A segunda forma é posta em oposição à primeira por se tratar de uma interação poligerida (a que a autora chama de "interação polêmica"), exemplificada por uma situação de debate televisivo, em que Proponente e Oponente se encontram em diálogo face a face, ao mesmo tempo em que se sabem vistos pelos espectadores do programa, no papel actancial de Terceiro. A terceira forma de polêmica acontece na relação entre um comentário postado na rede social Facebook, ao qual se seguem inúmeros comentários que acirram a controvérsia.

A temática, nas três situações, concerne ao uso da burca. A interação monogerida do primeiro caso, um artigo de opinião, de Bénedicte Charles, publicado em 2009 pela revista de esquerda Marianne, aborda um outro texto (um projeto de lei), por isso já se atesta como constitutivamente intertextual. $\mathrm{O}$ artigo nasce em reação a esse projeto de lei que propunha 
impedir o uso da burca nos espaços públicos da França na época e punir com multas os que infringissem a lei. Bénedicte Charles se coloca como um "narrador" que gerencia outros dizeres reportados na matéria, e por essa condição enunciativa joga com os pontos de vista que se embatem, conduzindo-os para um dado direcionamento. Citar e parafrasear segmentos de outros textos são expedientes prototípicos de intertextualidade. Trata-se da copresença de textos específicos mencionados no texto em foco.

No segundo caso, o debate televisivo entre um político e uma jovem francesa muçulmana também termina desembocando no uso do véu integral com o qual a jovem está vestida. Mas aqui os apelos intertextuais são de natureza muito mais ampla, porque correspondem a alusões, como referências vagas a diversos textos inespecíficos que tratam do direito da mulher de trajar ou não a burca e também de poder professar sua religião publicamente, sem ser acusada de estar escondendo sua identidade.

No terceiro caso, a polêmica se atualiza na postagem em um fórum de discussão igualmente relacionada ao artigo de Bénédicte Charles, na revista Marianne - portanto, outra ocorrência de metatextualidade, ou seja, o comentário de um texto por um outro texto, o que confere à modalidade polêmica, mais uma vez, o caráter intertextual.

Reafirmamos, assim, o que temos sugerido em textos anteriores (CAVALCANTE $e t$ alii, 2020): a atualização da modalidade argumentativa polêmica ocorre, necessariamente, em relações intertextuais em cada quadro interacional. $O$ texto de um dado gênero, como a charge, alude a alguma ocorrência já divulgada em textos anteriores, e, ao trazer à tona uma dicotomização de teses, a polêmica se completará provavelmente em outros textos. No exemplo abaixo, vemos um tuíte em resposta a um depoimento do presidente da Fundação Palmares, Sérgio Camargo, que criticou uma campanha de cervejaria, afirmando que a estrela presente na embalagem da cerveja Heineken era um "marketing da lacração para minorias doutrinadas". Reflitamos sobre os dois tuítes a seguir, printados do perfil de Mariza Brito: 
Figura 1 - Estrela do PT

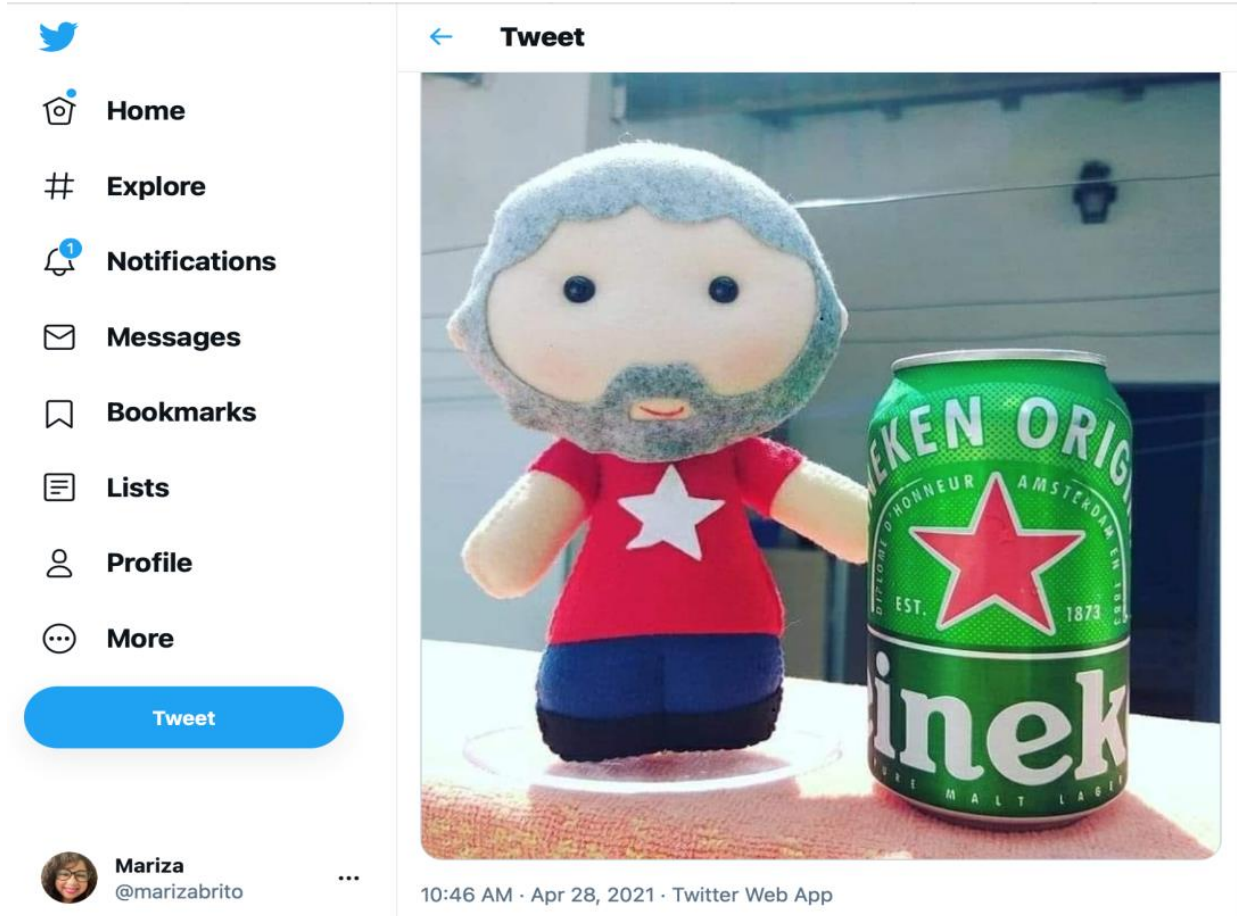

Fonte: https://twitter.com/orlandoguerreir/status/1387402818328403969.

Figura 2 - Gadólicos anônimos

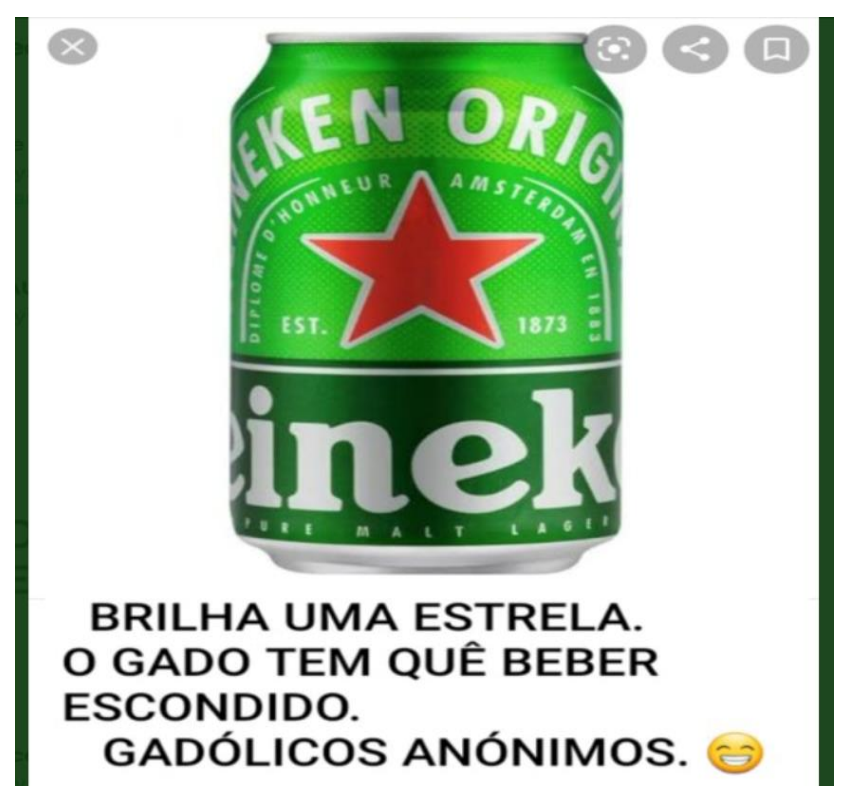

Fonte: https://twitter.com/orlandoguerreir/status/1387402818328403969.

Os dois exemplos aludem a um texto-fonte que reporta a fala do presidente da Fundação Palmares. Sérgio Camargo relaciona a estrela vermelha, que caracteriza a logomarca da cervejaria holandesa Heineken, fabricada desde 1864, com a estrela vermelha do Partido dos Trabalhadores (PT), fundado em São Paulo no ano de 1980. Nos dois textos, a fala de Sérgio 
Camargo é ridicularizada e criticada pelos tuiteiros. O bonequinho, representando o expresidente do Brasil, Lula, junto com a cerveja, é uma provocação ao presidente da referida fundação, já conhecido pelos brasileiros por suas enunciações polêmicas e por suas atitudes agressivas, por vezes até desrespeitosas. Uma dessas atitudes foi a exclusão dos quadros de mulheres negras, como Marina Silva e Benedita da Silva, da sala de homenagem do prédio da Fundação Palmares.

O segundo exemplo alude amplamente aos eleitores de Bolsonaro, tachados de "gado" pelos opositores, por suas posições negacionistas e reações sempre em defesa do Presidente Jair Bolsonaro, acusado por muitos de ter responsabilidade pelos mais de 465 mil brasileiros mortos na pandemia do Coronavírus. O emprego da expressão referencial "gadólicos anônimos" estabelece uma outra alusão a textos que tratam da associação dos Alcoólicos Anônimos do Brasil (AA), comunidade de caráter voluntário que ajuda homens e mulheres a lidar com o alcoolismo. Evidentemente, a alusão é favorecida pela anáfora indireta que liga a cerveja ao alcoolismo, mas também à anáfora indireta que liga o ex-presidente Lula a um suposto vício do álcool, e a muitas outras que geram gatilhos para várias questões polêmicas, principalmente as que envolvem política.

Com essas observações, reiteramos que, além de constituir um recurso para a argumentatividade, a intertextualidade é condição para a encenação da modalidade polêmica no espaço público. Vejamos como isto é construído a partir da charge a seguir.

Figura 3 - O caos vem aí
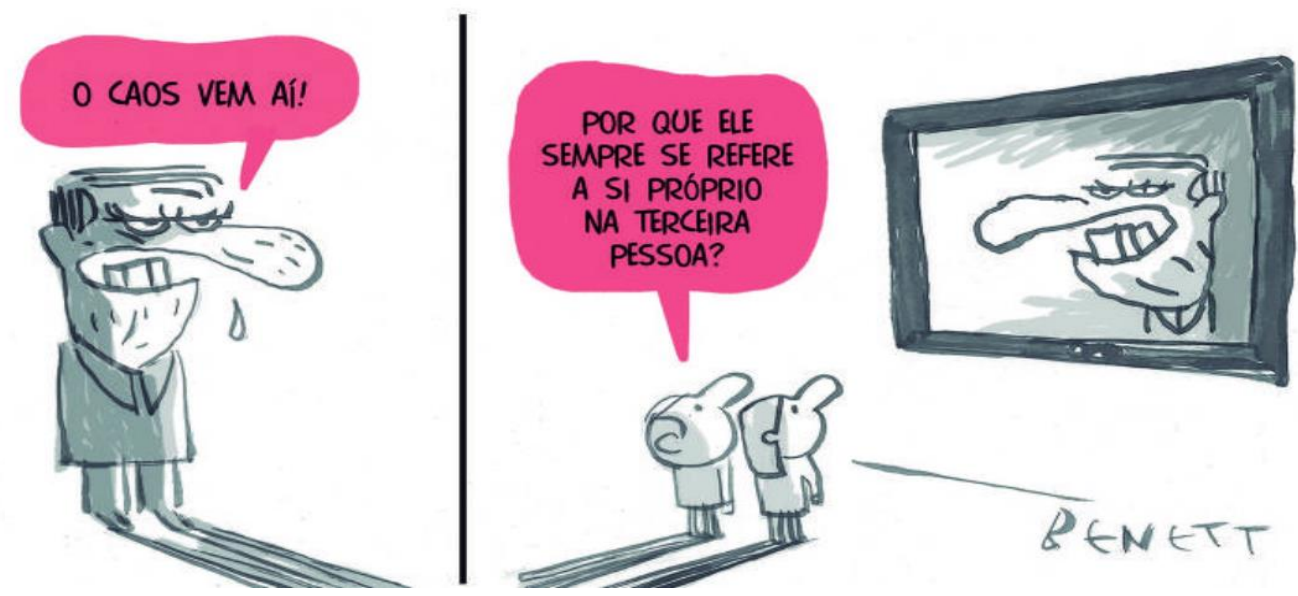

Fonte: https://fotografia.folha.uol.com.br/galerias/1692992027494251-charges-marco-2021.

A relação intertextual desta charge manifesta-se por meio de alusões amplas por se tratar de um diálogo entre este texto e um conjunto de outros textos que tratam da atuação do 
Presidente da República frente à Pandemia, com o propósito de marcar o ponto de vista do locutor, o chargista Benett.

No primeiro quadrinho, temos o anúncio feito pelo próprio Presidente: "o caos vem aí". Para o Presidente, representado na imagem como uma pessoa furiosa, o "caos" expressa seu desacordo e insatisfação, amplamente difundidos por ele próprio e seus aliados em declarações nas mídias digitais. Para defender-se, o presidente chama de "caos" as providências tomadas pelos governadores oposicionistas que respeitam a ciência e adotam medidas restritivas.

Sabe-se que esta atitude de desagrado do Presidente, expressa pela caricatura do primeiro quadrinho, também se estende aos ministros do Supremo Tribunal Federal, que garantem o direito constitucional de medidas preventivas dos Estados, ao Congresso Nacional e a alguns órgãos de imprensa.

No segundo quadrinho, o referente do "caos" é recategorizado como o próprio presidente, sob o ponto de vista do locutor, o que fica evidenciado na pergunta de um dos personagens: "Por que ele sempre se refere a si próprio na terceira pessoa?". Isto é, Bolsonaro é o próprio caos. Assim, esta charge retoma outros textos de vários gêneros que tratam do descaso do Governo Federal.

Vale destacar o repertório de frases bastante conhecidas e repetidas pelo presidente na Imprensa e nas redes sociais: "Como é fácil impor uma ditadura no Brasil", "País de maricas", “Resfriadinho", “E daí?”, “É mimimi”. Estas e outras frases, segundo matéria da Folha de SP (disponível no site da UOL), assinada por Julia Chaib e Renato Machado e publicada em 31 de abril de 2021, estão sendo investigadas pela CPI do Senado, instalada em 29/04/2021, sobre a Covid-19, mirando a atuação do Governo Federal no enfrentamento da Covid-19.

Assim, a argumentação do chargista se faz por meio de alusões amplas, numa interação monogerida, atualizando a polêmica e servindo como gatilho para outros textos que darão continuidade à encenação polêmica.

\section{Tomada de posição e categorias argumentativas axiológicas na polêmica}

Conforme dissemos, na modalidade argumentativa polêmica, há um desacordo irresolvível, no qual a interação entre os atores sociais, que assumem os papéis de Proponente, Oponente e Terceiro, é marcada por pontos de vista insignificados, desqualificados e silenciados. Esses atores sociais, como Proponentes e Oponentes, agem de formas variadas para marcar seu lugar de fala sobre um determinado tema, mas também para persuadir o Terceiro.

Essas tomadas de posição se manifestam de diversas maneiras, não somente por certos arranjos composicionais, pelos modos de interagir nas modalidades argumentativas e pelas 
escolhas lexicais, mas ainda pelos modos de apresentar e recategorizar os referentes e pela convocação de recursos intertextuais, conforme demonstramos neste trabalho. Essas estratégias, e tantas outras, apoiam-se em representações sociais, valores e crenças que os participantes do cenário enunciativo defendem.

A importância das noções de valor e de estereótipo na argumentação polêmica reside justamente na confrontação de pontos de vista, que são assumidos, ou não, pelos locutores em cada texto. Publicações de notícias em redes sociais são bons exemplos de interação em que os sujeitos selecionam e negociam referentes para a construção dos lugares de fala e manifestação de pontos de vista.

Crenças e valores dóxicos são usados para ancorar pontos de vista. Retomamos, nesse sentido, a noção de estereótipo, que faz parte das representações discursivas dos sujeitos. Amossy (2020) explora a noção em três grupos principais: semântica, enunciação (análise do discurso) e retórica argumentativa.

A estereotipia e a doxa (opinião comum) podem ser representadas como um tipo de raciocínio que se baseia no que é aceito e/ou verossímil, independentemente de sua comprovação científica, podendo marcar um limite entre usos mais consensuais ou mais controversos. As correntes retóricas costumam aproximar a noção de estereótipo à ideia de lugar-comum, convocando-a para o emprego de técnicas de persuasão, já que o acordo sobre os valores pode representar uma prova de sua validade. Assim, é possível afirmar que uma análise retórica que se vale da estereotipia visa "encontrar os elementos dóxicos constitutivos da argumentação em sua manifestação social e ideológica (ideias comuns, evidências compartilhadas, estereótipos)" (AMOSSY, 2020, p. 116). Amossy (2020) chega a uma possibilidade analítica pela distinção entre lugar-comum, ideia comum e estereótipo. $\mathrm{Na}$ modalidade polêmica, há por parte dos actantes um tipo de ancoragem em estereótipos, lugares e evidências comuns na comparação, por exemplo, com o uso de fatos e verdades. Citando Angenot e Eggs, Amossy (2020, p.112) constata que "a argumentação, associada à deliberação, ao debate ou à polêmica, revela um raciocínio sujeito a normas de racionalidade cuja chave é o plausível (e não o verdadeiro)".

\section{Conclusão}

Neste trabalho, refletimos sobre alguns traços característicos do que Ruth Amossy, em sua teoria da argumentação nos discursos (TAD), descreve como modalidade argumentativa polêmica. Partindo da perspectiva da Linguística Textual desenvolvida pelo grupo Protexto, ponderamos sobre os textos que integram as interações regidas pelo dissenso e salientamos duas 
condições de efetivação da polêmica no espaço público: a realização em interações concretas e as ligações necessariamente intertextuais.

Assumimos que o recurso às intertextualidades é uma condição de instauração da modalidade polêmica, uma vez que os textos que atualizam teses dicotômicas citam e parafraseiam fragmentos de outros textos, ou aludem a acontecimentos já reportados em textos diversos. Além disso, a modalidade polêmica termina por se ramificar em outros textos que comentam o texto-fonte, em relações de metatextualidade.

Essa assunção, base de nosso movimento analítico, possibilitou relacionar as intertextualidades ao embate de pontos de vista e às categorias axiológicas da argumentação: lugares, evidências, estereótipos e valores. A análise textual da argumentação polêmica tem muito a revelar não apenas sobre os modos de interação nos embates de uma sociedade democrática.

\section{Referências}

AMOSSY, R. Argumentação no discurso. São Paulo, Contexto, 2020.

AMOSSY, R. Linguística, retórica e análise do discurso. In: CAVALCANTE, M. M.; BRITO, M. A. P. (Orgs.). Texto, discurso e argumentação: traduções. Trad. Rosane Lorena de Brito, Mariza Angélica Paiva de Brito e Maria da Graça dos Santos Faria. Campinas: Pontes, 2020. p. 97-131.

AMOSSY, R. Apologia da polêmica. Coordenação da tradução Mônica Magalhães Cavalcante. São Paulo, Contexto, 2017.

AMOSSY, R. É possível integrar a argumentação na análise do discurso? Problemas e desafios. ReVEL, edição especial, v. 14, n. 12, p. 165-190, 2016.

AMOSSY, R. Contribuição da Nova Retórica para a AD: o estatuto do lógos nas Ciências da Linguagem. In: EMEDIATO, W.; LARA, G. M. P. (Orgs.). Análises do discurso hoje. vol. 4. Rio de Janeiro: Nova Fronteira, 2011. p. 1-14 (e-book).

AMOSSY, R. As modalidades argumentativas do discurso. In: LARA, G.; MACHADO, I.; EMEDIATO, W. (Orgs.). Análises do discurso hoje. vol. 1. Rio de Janeiro: Nova Fronteira, 2008. p. 231-254.

AMOSSY, R. Rhétorique et analyse du discours. Pour une approche socio-discursive des textes. In: ADAM, J. M.; HEIDMANN, U. (Orgs.). In: Sciences du texte et analyse de discours. Etudes de Lettres, 2005. p. 163-179.

CAVALCANTE, M. M. et al. Linguística Textual e argumentação. São Paulo: Ed. Pontes, 2020. 
CORTEZ, S. L. A construção textual-discursiva do ponto de vista: vozes, referenciação e formas nominais. 2011. 249 f. Tese (Doutorado em Linguística) - Programa de PósGraduação em Linguística, Universidade Estadual de Campinas, Campinas, 2011.

DASCAL, M; KNOLL, A. Cognitive Systemic Dichotomization in Public Argumentation and Controversies, Frank Zenker (éd.), Argumentation: Cognition and Community. Proceedings of the $9^{\text {th }}$ International Conference of the Ontario Society for the Study of Argumentation (OSSA), May 18-21, Windsor, ON (CD ROM), 1-35, 2011.

KING, A.; FLOYD, D. A. Nixon, Agnew, and the Silent majority: a case study in the rhetoric of polarization. western speech, 1971.

KOCK, C. Constructive controversy: rhetoric as dissensus-oriented discurse. Cogency, v. 1, p. 89-112, 2009.

MACEDO, P. S. A. de. Análise da argumentação no discurso: uma perspectiva textual. 2018. 245 f. Tese (Doutorado) - Programa de Pós-Graduação em Linguística, Universidade Federal do Ceará, Fortaleza, 2018.

PAVEAU, M.-A. L'Analyse du Discours Numérique. Dictionnaire des formes et des pratiques. Paris: Hermann Éditeurs, 2017.

PERELMAN, C.; OLBRECTHS-TYTECA, L. Tratado da argumentação. São Paulo: Martins Fontes, 2005.

PLANTIN, C. Dictionnaire de l'argumentation: Une introduction aux études d'argumentation. Lyon: ENS Éditions, 2016.

PINTO, R.; CORTEZ, S. Do pathos retórico à 'empatia rabateliana': argumentação emocionada em textos/discursos polêmicos. Revista de Letras, Fortaleza, v. 2, n. 36, p. 5162, jul./dez. 2017

RABATEL, A. Sujets modaux, instances de prise en charge et de validation. Le discours et la langue, Cortil-Wodon: Editions modulaires européennes, v. 6, n. 3-2, p. 13-36, 2012.

RABATEL, A. Homo narrans: por uma abordagem enunciativa e interacionista da narrativa: pontos de vista e lógica da narração: teoria e análise. Trad. $\mathbf{M}^{\mathrm{a}}$ das G. S. Rodrigues, Luís Passeggi, João G. da Silva Neto; revisão técnica João G. da Silva Neto. São Paulo: Cortez, 2016.

RABATEL, A. Du sens et de l'interprétation au prisme de la problématique translinguistique du point de vue. Orbis Linguarum, v. 50, 2018. 


\section{Sobre os autores}

Mônica Magalhães Cavalcante (Orcid iD: https://orcid.org/0000-0002-5561-3993)

É bolsista CNPq de Produtividade em Pesquisa nível PQ-1. Líder do Grupo de pesquisa PROTEXTO (UFC). Tem pós-doutorado em Linguística pela Unicamp. Desde 1989, é professora da Universidade Federal do Ceará. Membro do GT Linguística do Texto e Análise da Conversação, da Associação Nacional de Pesquisa em Letras e Linguística (ANPOLL). Tem experiência na área de Linguística Textual, com ênfase em referenciação, intertextualidade, metadiscursividade, argumentação, heterogeneidades enunciativas, gêneros do discurso, art0069culação tópica e sequências textuais.

\section{Mariza Angélica Paiva Brito (Orcid iD: https://orcid.org/0000-0001-5375-5480)}

Professora do Mestrado em Estudos da Linguagem e do Mestrado Interdisciplinar em Humanidades (Unilab); bolsista de Produtividade em Pesquisa da FUNCAP (BPI); professora adjunto da Universidade da Integração Internacional da Lusofonia Afro-brasileira (UNILAB); pós-doutora em Linguística de Texto, mestre e doutora em Linguística pelo Programa de Pós-Graduação em Linguística da UFC. Líder do GELT - Grupo de Pesquisa em Linguística Textual (CNPq / UNILAB) e vice-líder do PROTEXTO - Grupo de Pesquisa em Linguística (CNPq / UFC). Membro do GT Linguística do Texto e Análise da Conversação, da Associação Nacional de Pesquisa em Letras e Linguística (ANPOLL). Desenvolve pesquisas na área de Linguística Textual, heterogeneidade enunciativa e argumentação.

Evandro de Melo Catelão (Orcid iD: http://orcid.org/0000-0003-3006-5051)

Doutor em Letras pela Universidade Federal do Paraná (UFPR). Pós-Doutor na área de Linguística Textual pela Universidade Federal do Ceará (UFC). Professor do Magistério Superior da Universidade Tecnológica Federal do Paraná - Campus Curitiba e Professor do Programa de Pós-Graduação em Estudos de Linguagens - PPGEL no Campus Curitiba, membro do Grupo de Pesquisa PROTEXTO (UFC). Tem pesquisas diversas na área de Linguística Textual e ensino, estudando principalmente: gêneros do discurso, argumentação, retórica; leitura e produção de gêneros acadêmicos.

Maria da Graça dos Santos Faria (Orcid iD: https://orcid.org/0000-0002-2704-0497)

Mestrado e Doutorado em Linguística pela Universidade Federal do Ceará (UFC). Docente associado IV da Universidade Federal do Maranhão (UFMA). Membro do Grupo de Pesquisa Protexto (UFC). Coordenadora do Grupo de Pesquisa Estratégias e Procedimentos de Organização Textual (GEPOT). Professora do Programa de Pós-Graduação do Departamento de Letras da UFMA (PGLetras). Membro do GT em Linguística Textual e Análise da Conversação e membro do GT "Discurso e argumentação" da ANPOLL.

Ananias Agostinho da Silva (Orcid iD: https://orcid.org/0000-0001-5442-5133)

Doutor em Estudos da Linguagem. Professor adjunto da Universidade Federal Rural do Semi-Árido (UFERSA), atuando no Departamento de Ciências Humanas e no Programa de Pós-Graduação em Ensino (POSENSINO). É também professor permanente do Programa de Mestrado Profissional em Letras (PROFLETRAS), Unidade de Pau dos Ferros, da Universidade do Estado do Rio Grande do Norte (UERN). É líder do Grupo de Pesquisa em Estudos Linguísticos do Texto (GPELT/UFERSA), membro do Grupo de Pesquisa PROTEXTO (UFC) e do Grupo de Pesquisa em Análise Textual dos Discursos (ATD/UFRN). Membro do GT Linguística do Texto e Análise da Conversação, da Associação Nacional de Pesquisa em Letras e Linguística (ANPOLL). Desenvolve estudos em Linguística Textual, atuando principalmente nos seguintes temas: gêneros textuais, ensino de língua materna, argumentação e polêmica.

Suzana Leite Cortez (Orcid iD: https://orcid.org/0000-0003-0983-0900)

Doutora em Linguística pela UNICAMP, com estágio de doutorado sanduíche na Université de Lyon 2 - França, e Pós-Doutorado pela Université Sorbonne Nouvelle-Paris 3. É professora adjunto IV do Departamento de Letras e do Programa de Pós-Graduação em Letras (PPGL), da Universidade Federal de Pernambuco e líder do GESTO - Grupo de Estudos do Texto (CNPq/UFPE). Tem experiência na área de Linguística, com ênfase em Linguística textual, atuando principalmente nos seguintes temas: 
Revista (Con)Textos Linguísticos, Vitória, v. 15, n. 31, p. 48-65, 2021 | e-ISSN 1982-291X | ISSN 2317-3475

Revista do Programa de Pós-Graduação em Linguística da UFES | periodicos.ufes.br/contextoslinguisticos

referenciação, argumentação em textos, ponto de vista, heterogeneidade enunciativa, formação de professores e ensino de língua portuguesa.

Recebido em maio de 2021.

Aprovado em agosto de 2021. 